Int. J. Electrochem. Sci., 11 (2016) $7690-7704$

International Journal of

ELECTROCHEMICAL

SCIENCE

WWw.electrochemsci.org

\title{
Ultrathin NiOOH Nanosheets Directly Assembled on Reduced Graphene Oxide Surface as Electrocatalyst for Oxidation of Glucose and Reduced Glutathione
}

\author{
Su-Juan Li ${ }^{*}$,Wei Guo, Rui-Ting Liu, Ji-Min Du \\ Henan Province Key Laboratory of New Optoelectronic Functional Materials, College of Chemistry \\ and Chemical Engineering, Anyang Normal University, Anyang, 455000, Henan, China. \\ *E-mail: lemontree88@163.com
}

doi: $10.20964 / 2016.09 .20$

Received: 27 May 2016 / Accepted: 11 July 2016 / Published: 7 August 2016

The aqueous $\mathrm{NiOOH}$ with untrathin nanosheets structure were prepared using a hydrothermal strategy and characterized by atomic force microscopy (AFM), X-ray diffraction (XRD) and scanning electron microscopy (SEM). It was modified on electrochemically reduced graphene oxide electrode through a self-assembly method to form NiOOH/RGO nanocomposites electrode. SEM, energy-dispersive X-ray analysis and electrochemical impedance spectroscopy were employed to characterize the resultant $\mathrm{NiOOH} / \mathrm{RGO}$ nanocomposites electrode. To study the electrocatalytic properties of the NiOOH/RGO nanocomposites, glucose and reduced glutathione (GSH) were selected as model small molecules. An favorable electrocatalytic activities of the $\mathrm{NiOOH} / \mathrm{RGO}$ electrode was obtained toward oxidation of glucose and GSH. The present NiOOH/RGO nanocomposites based amperometric sensor showed a rapid and highly sensitive response to glucose and GSH, which might find promising applications in medical applications, biological fuel cells and diseases diagnosis.

Keywords: Nickle oxide hydroxide nanosheets; Reduced graphene oxide; Electrocatalyst; Glucose; Reduced glutathione

\section{$\underline{\text { FULL TEXT }}$}

(C) 2016 The Authors. Published by ESG (www.electrochemsci.org). This article is an open access article distributed under the terms and conditions of the Creative Commons Attribution license (http://creativecommons.org/licenses/by/4.0/). 